\title{
Produksi Program Musik Chamber Dalam Bentuk Video Dokumenter pada PT. Mata Air Inspirasi (SWARNA FMTV)
}

\author{
Listina Nadhia Ningsih ${ }^{1}$ \\ Ray Tri Nugroho ${ }^{2}$ \\ I Nyoman Lingga Anjana ${ }^{3}$ \\ ${ }^{1}$ Dosen STMIK Raharja \\ 2,3 Mahasiswa STMIK Raharja \\ 1,2,3 JL. Jendral Sudirman No.40,modern,Tangerang,021-5529692 \\ Email :listina.nadhia@raharja.info,ray.tri@raharja.info,lingga@raharja.info
}

\begin{abstract}
ABSTRAK
Kemajuan dibidang teknologi tidak dapat dipungkiri, bahwa banyak perusahaan yang bersaing untuk menjadi perusahaan ternama di Indonesia, ditambah dengan hadirnya pasar bebas asia dan kemajuan pada bidang broadcasting, terbukti dengan banyaknya stasiun televisi baru yang bermunculan dan siap untuk bersaing menjadi televisi terbaik di Indonesia, baik dari televisi teresterial maupun televisi digital. PT. Mata Air Inspirasi (SWARNA FMTV) saat ini bergerak pada konten televisi digital. Tayangan yang sudah ada sebelumnya di SWARNA FMTV yaitu jenis konten program talkshow, current affair, video clip, feature, dan belum mempunyai konten program dokumenter. Tujuan Penelitian ini adalah mengajak masyarakat khususnya para pecinta musik chamber untuk memanfaatkan taman suropati sebagai tempat latihan para seniman musik. Musik chamber inilah yang akan di sajikan oleh SWARNA FMTV untuk mengisi jenis program televisi dokumenter. Musik chamber ini sebelumnya sudah disajikan oleh station televisi dalam bentuk soft news, dan pada penelitian ini akan mengangkat lebih detail tentang musik chamber dalam bentuk dokumenter. Metodologi yang digunakan dalam penelitian ini adalah analisa permasalahan, pengumpulan data, analisa perancangan media, dan konsep Produksi Media (KPM). Melalui perancangan video dokumenter musik chamber ini diharapkan agar dapat menjadi daya tarik dan bermanfaat bagi masyarakat dalam menyampaikan informasi mengenai hal-hal yang berkaitan dengan musik chamber, mencapai target pasar dalam meningkatkan presentasi minat masyarakat untuk menonton konten program SWARNA FMTV.
\end{abstract}

Kata Kunci : Video Dokumenter, Media, Musik Chamber, Televisi Digital, Program Musik.

\begin{abstract}
Progress in Technology can not be denied, that Many Companies Competing for review Become a reputed Company in Indonesia, plus WITH presence of the Free Market asia And Progress AT field of broadcasting, Proven with many Television newly Yang sprung And Ready for a review of competing Become Best Television in Indonesia, both from terrestrial television and digital television. PT. Spring Inspiration (Swarna FMTV) When ON Moving Singer digital television content. Impressions Already earlier in Swarna FMTV ADA Namely TYPE talk show program content, current affairs, video clips, features, and yet has a documentary program content. Objective singer is inviting 'people, especially chamber music lovers to review utilizing Suropati Park as a place exercise the musical artist. This chamber music Yang will be presented for review by Swarna FMTV Charge Operating documentary television program. Music Singer space previously had been presented by television stations hearts Forms of soft news, Dan Singer will Lifted Research ON MORE ABOUT detailed documentary Form hearts music room. Research Methodology Used hearts Singer is a problem Data Analysis, collection, analysis of media design, and concept Media Production (KPM). Through the design of documentary video music hall singer can be expected that the appeal of Being helpful and Share hearts convey information society Regarding relates THINGS WITH chamber music, achieving Vol.3 No.1 - Februari 2017
\end{abstract}


market targets hearts improve the presentation of Interest 'community to review watch Swarna FMTV Program Content.

Keywords: Video Documentary, Media, Music Chamber, Television Digital, Program Music.

\section{PENDAHULUAN}

Sejalan dengan berkembangnya zaman teknologi digital sudah memiliki kemajuan yang sangat pesat, siaran TV berawal dari teknologi analog dengan bertahap digantikan dengan tools yang berkerja dengan teknologi digital, seperti alat perekam, camera video dan perangkat editing. Beberapa manfaat dari pengunaan teknologi digital adalah penghematan penggunaan bandwidth spektrum frekuensi radio dikarnakan adanya teknik kompres terhadap jaringan tersebut.

PT. Mata Air Inspirasi (SWARNA FMTV) merupakan perusahaan yang bergerak dibidang pertelevisian digital yang berada di Jl. H. Midar, Pondok Pinang, Kebayoran Lama, Jakarta Selatan, 12310. SWARNA FMTV merupakan perusahaan yang bergerak dibidang pertelevisian digital yang dibutuhkan untuk memberikan informasi dan hiburan kepada masyarakat. Lembaga ini dipimpin oleh Erry Farrid, M.I.Kom selaku CEO SWARNA FMTV.

Saat ini bentuk program televisi yang dapat dinikmati oleh masyarakat diantaranya Teen Hits Update, Paramesuara, Bengkel Sinema dan Musik Chamber. Beberapa program yang sudah ditanyangkan oleh SWARNA FMTV seperti current affair, feature, talkshow dan video clip. SWARNA FMTV belum memiliki program televisi bergenre dokumenter, dalam video dokumenter ini akan diambil tema Musik Chamber yang akan dikemas dengan detail. Musik Chamber adalah komunitas musik dimana komunitas tersebut sangat peduli terhadap musik bangsa Indonesia. Dilandasi oleh cita-cita dan harapan untuk membangkitkan budaya Indonesia, sebagai tanda cinta dan hormat kepada ibu pertiwi, musik chamber berlokasi di Taman Suropati Menteng Jakarta Pusat.

Dengan adanya program baru mengenai video dokumenter musik chamber diharapkan dapat memberikan informasi yang lebih menarik tentang dunia musik yang mudah diterima oleh masyarakat luas dan tidak hanya menjadikan hiburan baru tetapi masyarakat dapat menjadikan musik chamber sebagai edukasi dan kreasi dalam dunia musik.

\section{RUMUSAN MASALAH}

Saat ini bentuk program televisi yang dapat dinikmati oleh masyarakat diantaranya Teen Hits Update, Paramesuara, Bengkel Sinema dan Musik Chamber. Beberapa program yang sudah ditanyangkan oleh SWARNA FMTV seperti current affair, feature, talkshow dan video clip. SWARNA FMTV belum memiliki program televisi bergenre dokumenter, dalam video dokumenter ini akan diambil tema Musik Chamber yang akan dikemas dengan detail. Musik Chamber adalah komunitas musik dimana komunitas tersebut sangat peduli terhadap musik bangsa Indonesia. Dilandasi oleh cita-cita dan harapan untuk membangkitkan budaya Indonesia, sebagai tanda cinta dan hormat kepada ibu pertiwi, musik chamber berlokasi di Taman Suropati Menteng Jakarta Pusat. 


\section{LANDASAN TEORI}

\section{Konsep Dasar Produksi}

Produksi adalah suatu upaya merubah bentuk sinopsis menjadi audio visual seperti yang telah diketahui bahwa pelaksanaan produksi sebuah program acara tergantung pada tuntutan sinopsis hal tersebut dikarenakan sinopsis merupakan hasil dari penemuan ide atau gagasan mengenai suatu program acara. ${ }^{[10]}$

\section{Pengertian Media}

Media adalah segala bentuk yang digunakan untuk menyalurkan informasi. Pengertian media yang diberikan AECT (Association for education communication and tecnology) ini menunjukkan bahwa istilah "media" memiliki makna yang sangat umum. ${ }^{[2]}$

\section{Konsep Dasar Program Siaran Televisi}

Televisi adalah alat penangkap siaran bergambar, yang berupa audio visual dan penyiaran videonya secara broadcasting. Istilah ini berasal dari bahasa yunani yaitu tele (jauh) dan vision (melihat), jadi secara harfiah berarti "melihat jauh", karena pemirsa berada jauh dari studio tv. Televisi dalam zaman modern ini sudah berkembang cukup pesat. Bentuknya pun kini beragam. Dari zaman yang berbentuk tabung hingga sekarang yang berbentuk LCD ( Liquid Crystal Display). Televisi adalah media pandang sekaligus media dengar (audio-visual). ${ }^{[4]}$

\section{Pengertian Video}

video merupakan gabungan gambar-gambar mati yang dibaca berurutan dalam suatu waktu dengan kecepatan tertentu. Gambar-gambar yang digabung tersebut dinamakan frame dan kecepatan pembacaan gambar disebut dengan frame rate, dengan satuan fps (frame per second). Karena dimainkan dalam kecepatan yang tinggi maka tercipta ilusi gerak yang halus, semakin besar nilai frame rate maka akan semakin halus pergerakan yang ditampilkan. ${ }^{[1]}$

\section{Video Dokumenter}

Dokumenter adalah suatu film yang mengandung fakta dan subjektivitas pembuatnya, artinya apa yang kita rekam memang berdasarkan fakta yang ada namun dalam penyajiannya kita juga memasukkan pemikiran - pemikiran kita. ${ }^{[6]}$

\section{SWARNA FMTV}

PT. Mata Air Inspirasi (SWARNA FMTV) merupakan perusahaan yang bergerak dibidang pertelevisian digital yang berada di Jl. H. Midar, Pondok Pinang, Kebayoran Lama, Jakarta Selatan, 12310. SWARNA FMTV merupakan perusahaan yang bergerak dibidang pertelevisian digital yang dibutuhkan untuk memberikan informasi dan hiburan kepada masyarakat. Lembaga ini dipimpin oleh Erry Farrid, M.I.Kom selaku CEO SWARNA FMTV. 


\section{LITERATURE RIVIEW}

1. Penelitian yang dilakukan oleh Wardhani dkk pada tahun 2014 dengan judul " PERANCANGAN VIDEO DOKUMENTER "AUTISME" " menjelaskan bahwa penelitian tersebut adalah Saat ini anak berkebutuhan khusus bisa ditemukan di mana mana. Salah satunya yaitu Autisme. Autisme adalah gejala menutup diri secara total, dan tidak mau berhubungan lagi dengan dunia luar, keasyikan ekstrim dengan pikiran dan fantasi sendiri. Penyebab autisme berbagai macam dan tidak dapat dihindari dalam kehidupan. Oleh karena itu autisme ini merupakan sebuah hal yang tidak bisa dihindari dan bisa menimpa siapa saja. Autisme di dunia terus bertambah, sayangnya di Indonesia sendiri autisme belum terlalu diperhatikan. Video dokumenter ini dibuat untuk mensosialisasikan tentang autisme kepada masyarakat agar timbul rasa kepedulian dan "awareness" terhadap autisme ini. ${ }^{[11]}$

2. Penelitian yang dilakukan oleh Iwan pada tahun 2013 dengan "PERANCANGAN VIDEO DOKUMENTER OLAHRAGA EKSTRIM "SKATEBOARD" SURABAYASK8" yang menjelaskan tentang Merancang olahraga dokumenter Video SurabayaSk8 tidak esktrim video skateboard skateboard penuh aksi dan juga juga tidak membosankan dan penuh dramatisasi film dokumenter. Esktrim olahraga Video skateboarding dokumenter menceritakan kisah kehidupan nyata SurabayaSk8. Pemain skateboard surabaya ke depan untuk memperjuangkan apa yang mereka yakini. Mereka berbagi suka, duka dan tawa dalam video dokumenter olahraga esktrim skateboard SurabayaSk8. Shooting teknik dan proses editing sesuai dengan literatur untuk menjadi acuan dalam desain ekstrim olahraga skateboard video dokumentasi SurabayaSk8. Merancang skateboard surabayask8 olahraga ekstrim video dokumentasi menggunakan teknik editing gerakan lambat dengan kamera yang mampu merekam hingga 60fps peristiwa membuat video yang terlihat menarik. Nada yang digunakan wana menggunakan warna-warna cerah untuk berbaur efek kebocoran cahaya di beberapa bagian transisi. Desain video dokumenter ini dibuat dengan tujuan memperkenalkan SurabayaSK8 olahraga ekstrim skateboard dan skateboard teknik media pembelajaran. ${ }^{[5]}$

3. Penelitian yang di lakukan oleh Oktavia pada tahun 2015 dengan judul "Perancangan Film Dokumenter "Ketika Hati Berbicara, Udara Membisikkannya Lewat Telingaku" menjelaskan bahwa penelitian tersebut adalah Film Dokumenter merupakan salah satu genre film atau salah satu wujud bentuk komunikasi visual dan verbal. Dengan mewujudkan kedua elemen visual, dan verbal diharapkan informasi dan pengetahuan yang akan diinformasikan kepada penonton atau khlayak umum dapat ditangkap dengan baik. Penggunaan Film Dokumenter dengan perpaduan beberapa teori yang dipakai dalam film dokumenter seperti, exspositori yang dipadukan menggunakan pendekatan visual 4P (Purpose,People, Plote, Place) diharapkan memberikan varian baru dalam penciptaan sebuah karya Film Dokumenter. Hasil dari perancangan dan penelitian ini adalah bahwa disabilitas/ berkebutuhan khusus terutama tuli yang dinggap identik dengan bodoh, atau mereka yang tidak bisa melakukan apa-apa, di sinilah mereka membuktikan bahwa anggapan kita selama ini tentang mereka salah. Mereka memang tuli namun, mereka juga bisa melakukan apa yang kita lakukan bahkan lebih dari yang kita bisa. Disinilah mereka menunjukan bahwa tuli juga bisa, mampu, dan sama seperti kita orang-orang normal lainnya, mereka punya mimpi, masa depan, dan mereka juga bisa merasakan dan mendengar bagaimana suara dan bunyi itu dengan hati dan detak jantungnya. ${ }^{[7]}$

4. Penelitian yang dilakukan oleh Putri dkk pada tahun 2013 dengan judul "PERANCANGAN VIDEO DOKUMENTER BATIK KHAS DI PEKALONGAN" 
menjelaskan bahwa penelitian tersebut adalah sebuah penelitian tentang motif Jlamprang dan Buketan merupakan batik khas di kota Pekalongan. Keunikan dari batik jlamprang dan buketan iaah motif dan warna yang beranekaragam. Seiring berjalannya waktu masyarakat semakin kurang mengerti tentang batik khas di Pekalongan, sehingga kesadaran masyarakt daam meestarikan dan menjaga warisan budaya juga semakin berkurang. Berdasarkan masalah yang sedang dihadapi, solusi dalam penyampaian inforamsi yang ditujukan kepada masyarakat dipiih daam bentuk video dokumenter. Perancangan video dokumenter yang berisi informasi mengenai batik khas di Pekalongan, memliki tujuan agar masyarakat sadar akan pentingnya menjaga dan melestarikan warisan budaya bangsa yang sudah melekat erat dengan kota Pekalongan. ${ }^{[9]}$

5. Penelitian yang dilakukan oleh Putra pada tahun 2014 dengan judul "PERANCANGAN VIDEO DOKUMENTER PENAMBANG PASIR SUNGAI PROGO KECAMATAN SRANDAKAN " menjelaskan bahwa penelitian tersebut adalah Kemajuan di era globalisasi sangat berpengaruh pada komputer teknologi. Penyiaran telah mengubah budaya media interaktif hari ini sebagai gaya hidup dan mendukung pekerjaan ekspresi dalam desain, audio, animasi, teks dan gambar akan dibahas dalam aplikasi multimedia. ilmu multimedia menyediakan mengesankan aksen pada elemen untuk mengejar bidang ini, dan itu termasuk pemutar audio dan video. Keuntungan video dokumenter ini memberikan gaya baru bersosialisasi yang mudah digunakan perlengkapan audio visual untuk mendukung proses informasi untuk memahami pentingnya dampak balance. Lingkungan pada perilaku penambang pasir Srandakan bahwa melalui oleh Progo sungai. Pentingnya alam melestarikan informasi runtuh dua pilar Progo lama jembatan yang menghubungkan kabupaten Srandakan dengan Kabupaten Brosot pada tahun 2000 karena gerusan di bawah sungai. ${ }^{[8]}$

6. Penelitian yang dilakukan oleh Emriadi pada tahun 2014 dengan judul "PERANCANGAN VIDEO FEATURE DOKUMENTER INDUSTRI TAMBANG BATU KAPUR BUKIT TUI PADANG PANJANG" menjelaskan bahwa penelitian tersebut adalah kapur industri yang beroperasi di padang kota Panjang telah tajuk setelah lama sejak zaman Belanda kolonial sampai sekarang. sektor pembangunan pertambangan dalam pengolahan sumber daya alam telah lama dikeluarkan oleh Padang Panjang pemerintah kota sebagai salah satu strategi dan kebijaksanaan penting untuk mendorong pertumbuhan ekonomi lokal. Selama industri kapur ini panjang dipelihara secara individual, dengan menggunakan dana swasta oleh pengusaha kapur dan kurangnya arah pola goverment.The oleh pertambangan, proses pembakaran, dengan cara dari kemasan promosi dan pemasaran masih konvensional . Dari latar belakang ini, desainer tertarik untuk membuat desain fitur video kapur tambang dokumenter Upaya Bukit Tui menginformasikan kapur industri yang sangat membutuhkan arah dari pemerintah untuk bekerjasama. $^{[3]}$

\section{METODOLOGI PENELITIAN}

Metode penelitian yang digunakan untuk Produksi Program Musik Chamber Dalam Bentuk Video Dokumenter yaitu sebagai berikut : (1) Metode Analisa Permasalahan yang dididapatkan dengan hasil interview melalui stakeholder pada SWARNA FMTV. (2) Metode Pengumpulan Data yang dilakukan dengan cara observasi, interview serta studi pustaka. (3) Metode Analisa Perancangan Media. Media video dokumeter musik chamber yang dibutuhkan oleh SWARNA FMTV yang nantinya diproduksi menggunakan software editing 
yaitu sebagai berikut : 1. Addobe Premiere Pro CC, 2. Adobe After Effect Pro CC, 3. Adobe Illustrator Pro CC. (4) Metode Kosep Produksi Media (KPM), diantaranya sebagai berikut :

\section{Preproduction}

Beberapa tahapan preproduction dalam pembuatan Video Dokumenter Musik Chamber, dimulai dengan cara observasi lapangan dan mengumpulkan data-data yang dibutuhkan, lalu dituangkan dalam sebuah gagasan secara sistemastis, agar mendapatkan hasil video dengan baik. Dalam penelitian ini media informasi yang digunakan yaitu Televisi Digital dengan konsep video dokumenter musik chamber dengan menggunakan packaging feature agar penonton tidak bosan dengan kemasan videonya.

Preproduction, production dan postproduction.

\section{PEMBAHASAN}

Untuk merancang sebuah media audio visual khususnya video dokumenter musik chamber, dibutuhkan beberapa tahapan dalam konsep produksi Mavib (KPM), adapun tahapan yang perlu dilakukan ialah preproduction, production, dan postproduction.

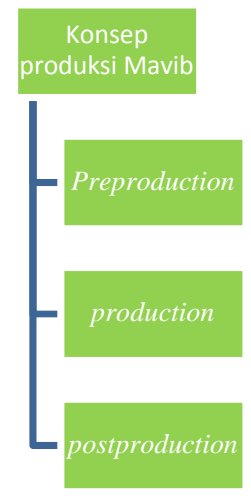

\section{Gambar 1. Konsep Produksi Mavib}

Video dokumenter musik chamber yang menarik ditunjukan kepada masyarakat luas, yang di lengkapi dengan pembuatan sinopsis, script writting serta storyboard. Ada tahapan yang terakhir yaitu pemilihan coloring. Semua tahapan harus sesuai dengan time schedule yang diterapkan. Untuk lebih jelasnya dijelaskan pada bagan berikut ini : 


\section{PREPRODUCTION}

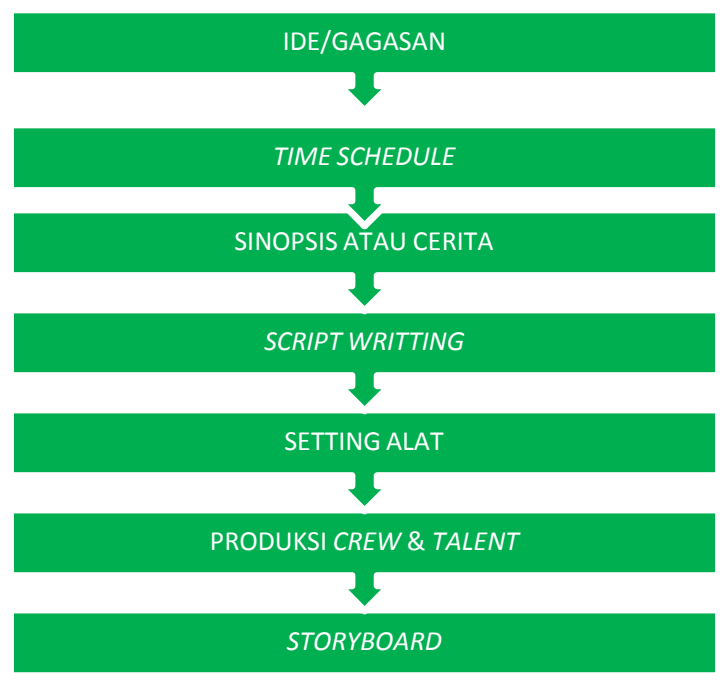

Gambar 2. Preproduction

\section{Observasi}

Pengamatan yang telah dilakukan kepada SWARNA FMTV, mengenai sudah atau tidak adanya video dokumenter musik chamber, dalam setiap program televisi yang diproduksi oleh SWARNA FMTV.

Ide

SWARNA FMTV ingin meningkatkan program acara televisi mengenai video dokumenter budaya musik Indonesia. Media video dokumenter salah satu media yang sangat efektif untuk menyampaikan informasi dan edukasi tentang budaya musik Indonesia, sehingga bisa menarik, memudahkan masyarakat yang ingin mengetahui tentang musik chamber yang ada di Taman Suropati Jakarta Pusat dan dapat menunjang efektifitas dalam proses musikalitas.

\section{Sinopsis}

"Taman Suropati awalnya bernama Burgemeester Bisschopplein, yaitu nama sebuah taman di Jakarta. Taman ini merupakan pusat kawasan Menteng, berada tepat di antara pertemuan tiga jalan utama yaitu Menteng Boulevard (Jl. Teuku Umar), Orange Boulevard (Jl. Diponegoro), dan Nassau Boulevard (Jl. Imam Bonjol). Taman Suropati yang rindang, sejak beberapa tahun yang lalu dihiasi patung-patung karya pematung dari seluruh ASEAN. Di Taman Suropati setiap minggunya banyak aktivitas yang dilakukan oleh masyarakat sekitar untuk olahraga, liburan di taman, dan ada yang bermain dan belajar musik, seperti komunitas Musik Chamber. Komunitas Musik Chamber mempunyai alur lagu daerah yang dikemas oleh alat musik classical, seperti biola, cello, flood, klarinet, fagot dan masih ada yang lain. Komunitas Musik Chamber bergerak pada tahun 2006 yang dimotori oleh Agus Tinus Esti Dwiharso dan rekan-rekannya. Melihat peluang untuk memanfaatkan fasilitas publik yang tidak digunakan dalam hal positif, maka Agus membuat sebuah Komunitas musik Vol.3 No.1 - Februari 2017 
chamber yang mempunyai ide dasar ialah musik kamar yang berada di taman. Dari situ Agus dan rekan-rekan memiliki option kepada masyarakat Jakarta untuk mengajak dan melakukan kegiatan di taman suropati, dan memiliki konsep rekreatif, edukatif, dan kreatif. Taman Suropati musik chamber mulai aktivitasnya pada hari minggu pukul 10.00 wib.

\section{Storyboard}

Storyboard merupakan sebuah gambar sket yang dilengkapi dengan petunjuk ataupun cacatan pengambilan gambar pada sebuah video untuk kebutuhan pembuatan film. Selama proses production berlangsung pengembangan yang berhubungan dengan video promosi pariwisata yang akan dibuat membutuhkan storyboard sebagai media pembantu. Adapun storyboard dalam video promosi pariwisata Kota Tangerang pada Dinas Porparekraf adalah sebagai berikut :

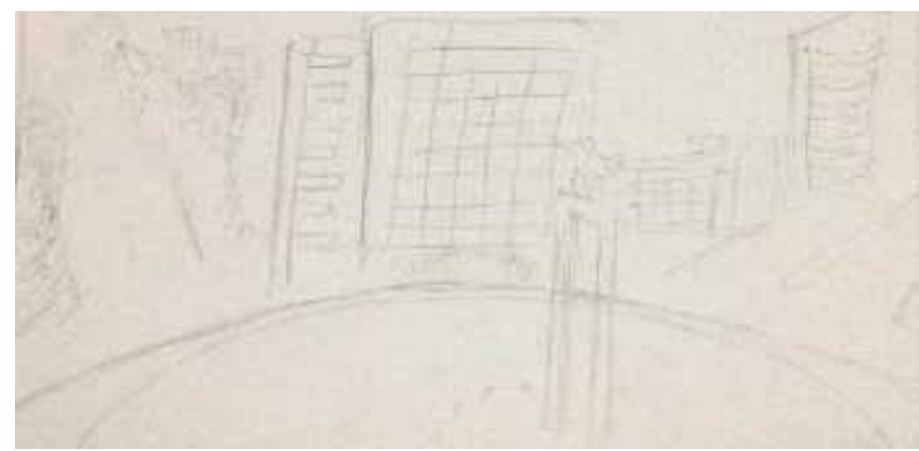

Gambar 3. EXT/Bunderan HI/Day/Full Shot Menampilkan timelapse patung bunderan HI

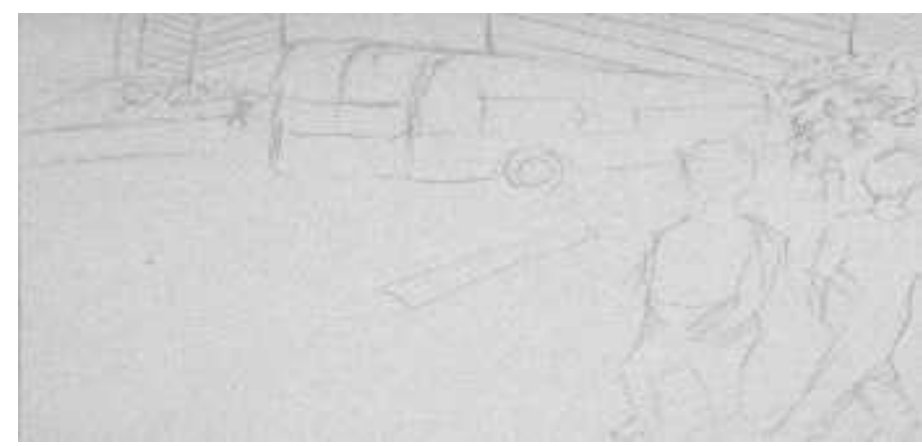

Gambar 4. EXT/Jakarta/Day/Full Shot Menampilkan suasana kota jakarta

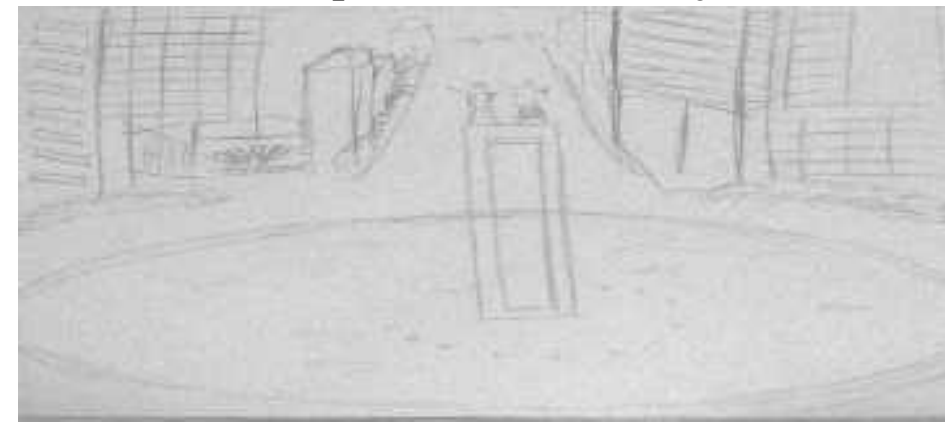

Gambar 5. EXT/Bunderan HI/Day/Long Shot Menampilkan suasana aktivitas bunderan HI pada hari Minggu 


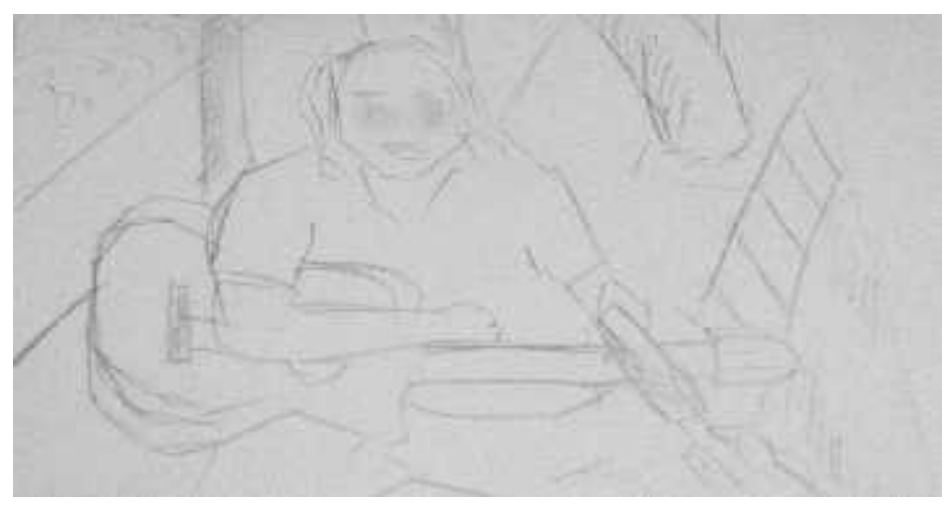

Gambar 6. EXT/Taman Suropati/Day/Medium Shot Menampilkan wawancara narasumber Ages Dwiharso

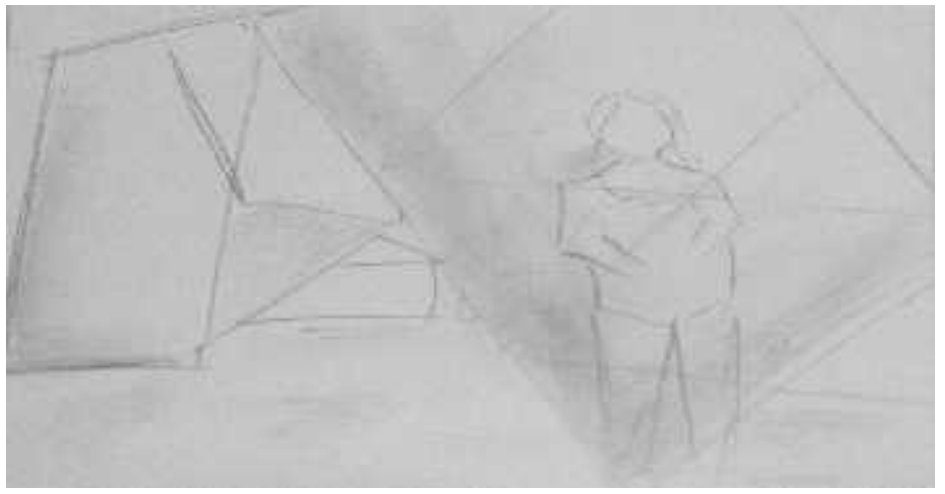

Gambar 7. EXT/Taman Suropati/Day/Two Shot Menampilkan suasana taman Suropati

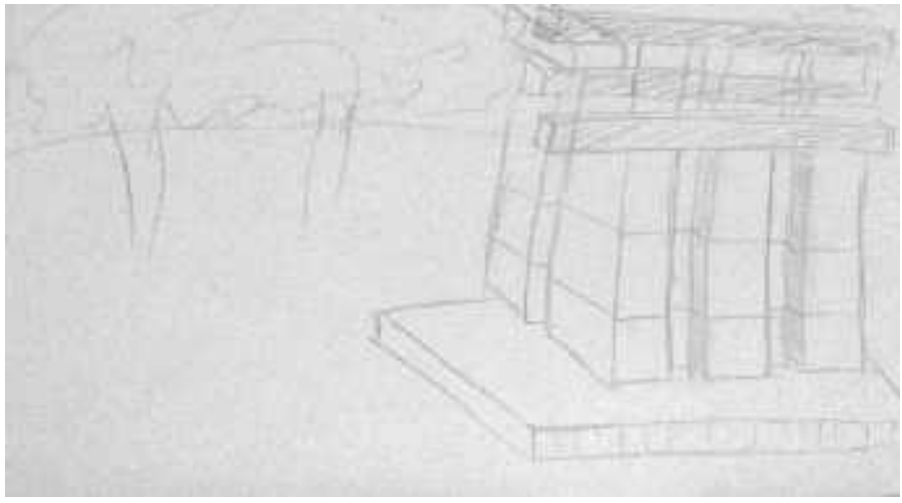

Gambar 8. EXT/Taman Suropati/Day/Full Shot Menampilkan patung - patung yang ada di taman Suropati 


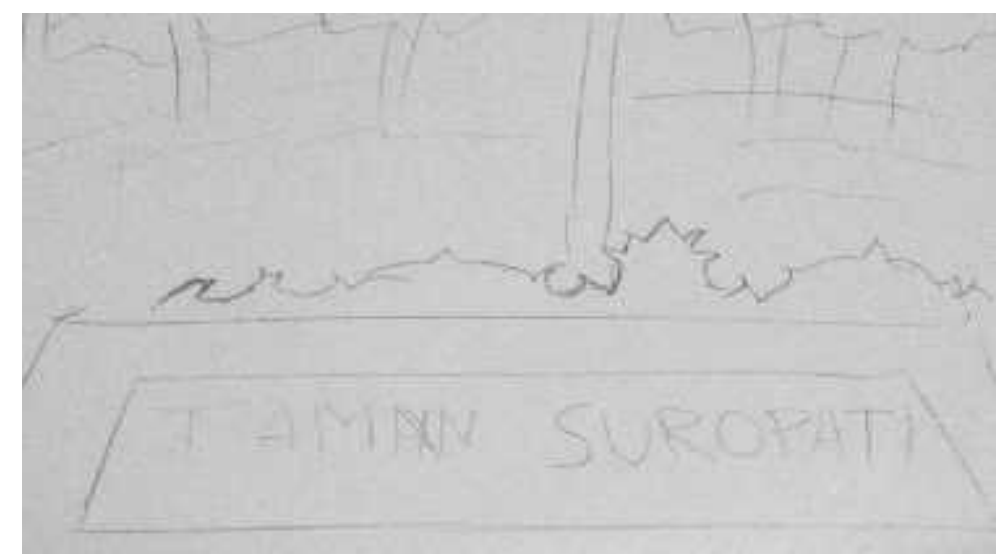

Gambar 9. EXT/Taman Suropati/Day/Full Shot Menampilkan tulisan taman Suropati

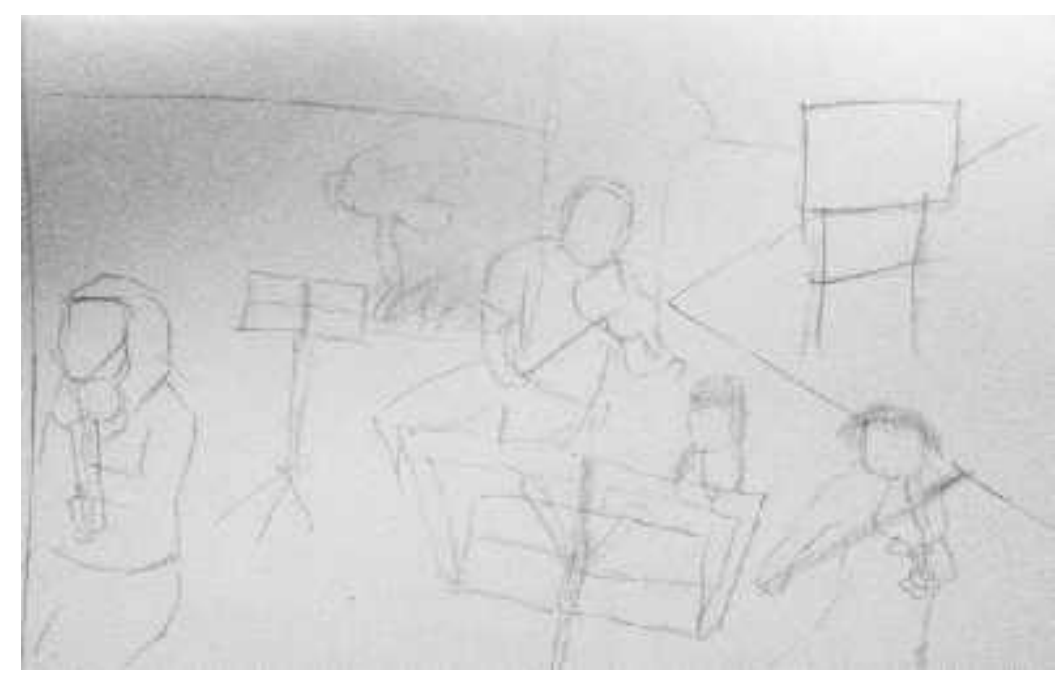

Gambar 21. EXT/Taman Suropati/Day/Group Shot Menampilkan suasana anak - anak yang sedang latihan biola

\section{Setting Alat}

Dalam setiap proses pembuatan video selalu dibutuhkan alat bantu untuk membuat video diantaranya yaitu : Camera, Tripod, Lighting serta Mic Camera. Selain itu camera yang digunakan untuk memproduksi video promosi pariwisata Kota Tangerang adalah camera Canon 7D, Canon 60D, Sony PD177 dan Sony Z7. adapun equipment camera yang digunakan adalah Tripod, Slider, Mic Recorder.

\section{Production}

Tahapan Production adalah proses pengambilan gambar atau biasa disebut dengan shooting. Dalam proses ini dibagi menjadi beberapa tahapan yaitu : 
a. Perencanaan multi media yang diperlukan ada tiga tahap element sistematis antara lain teks, gambar, serta suara. Kemudian di kombinasikan menjadi suatu file yang berbentuk video. Perencanaan multimedia didasarkan dengan konsep yang efektif agar menjangkau masyarakat untuk memperoleh informasi secara efisien dan akurat.

b. Perencanaan audio berperan sangat penting untuk penyampaian informasi dalam bentuk suara. Jika tidak ada audio video yang diputar kurang memuaskan. Karena jika tidak ada audio, langkah yang ditempuh yaitu dengan memperbanyak teks.

c. Perencanaan visual yang dihasilkan yaitu keseluruhan dari penggabungan gambar, teks, dan suara yang menghasilkan suatu video yang utuh untuk digunakan memberikan informasi. Dengan menggabungkan teks dan format penulisan yang sudah di tentukan, gambar yang sudah di produksi sebelum nya dan suara yang di keluarkan dari hasil membaca naskah kemudian di edit dan di export lalu mendapatkan video yang siap untuk di pergunakan.

d. Perencanaan Broadcasting difungsikan untuk menjangkau masyarakat dengan program pendistribusian efisien dan efektif. Dibuatnya perencanaan Broadcasting bertujuan untuk mencakup ruang lingkup masyarakat luas dengan memberikan informasi tentang musik chamber yang terletak di taman suropati. Dengan dibuat nya perencanaan broadcasting suatu media informasi menjadi arahan agar dapat mencapai target.

\section{GAMBAR REAL}

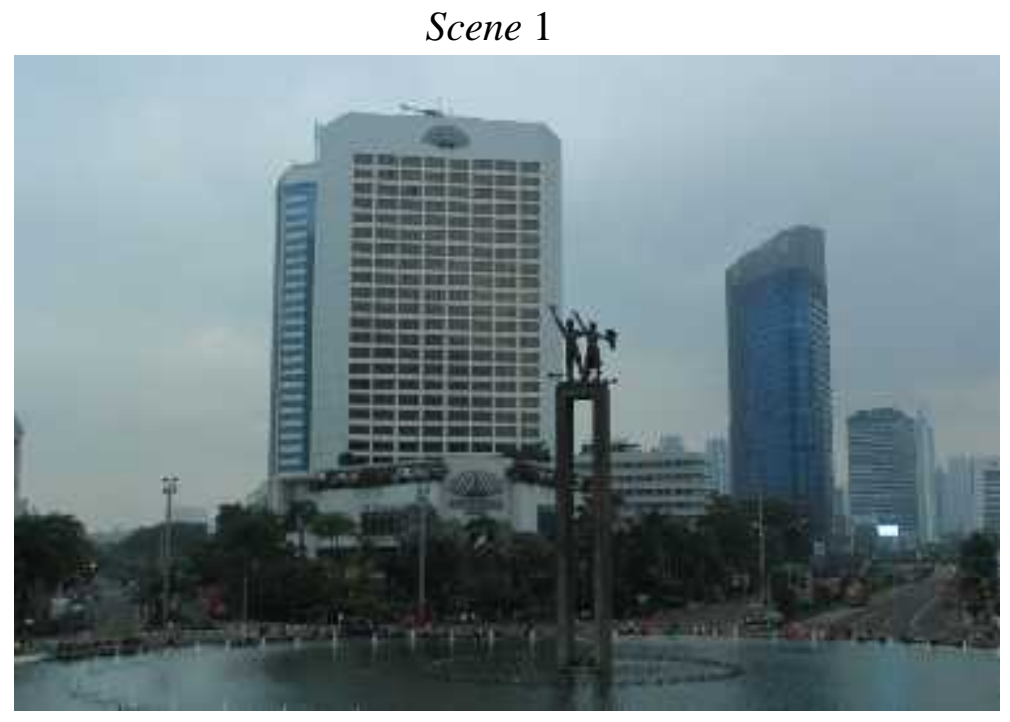

EXT/Bunderan HI/Day/Full Shot

Timelapse patung bunderan HI 
Scene 2

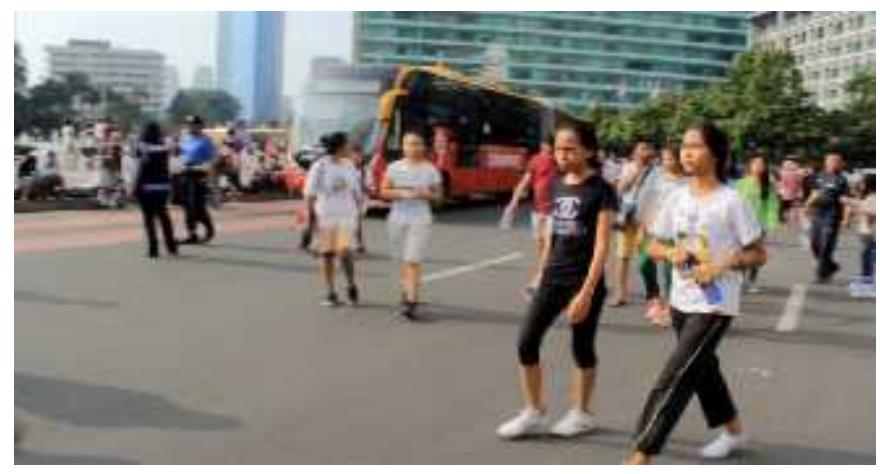

EXT/Jakarta/Day/Full shot

Suasana Kota Jakarta

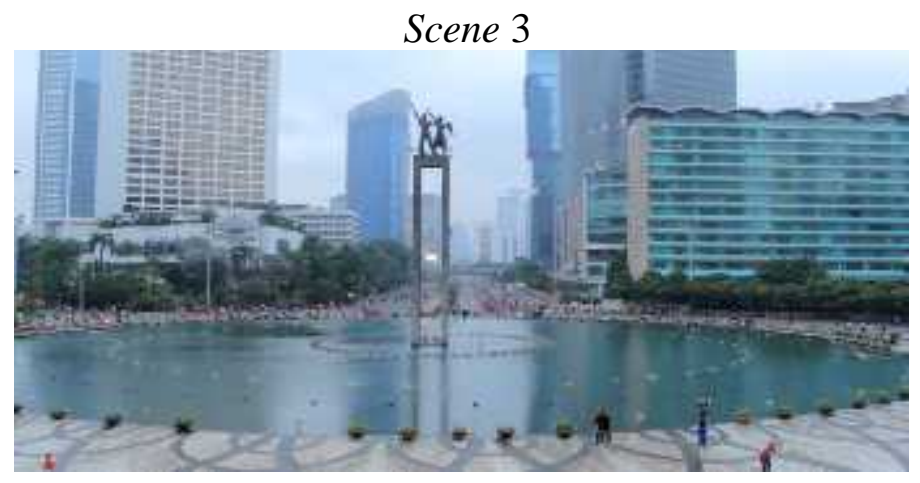

EXT/Bunderan HI/Day/long shot

Suasana aktivitas Bunderan HI pada hari Minggu

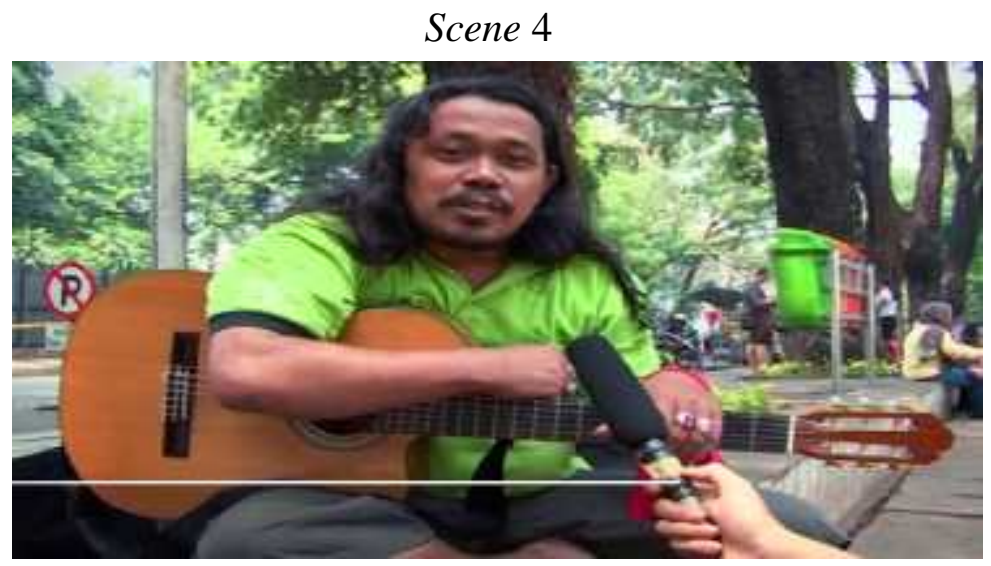

EXT/Taman Suropati/Day/Medium shot

Wawancara Narasumber Ages Dwiharso 


\section{Scene 5}

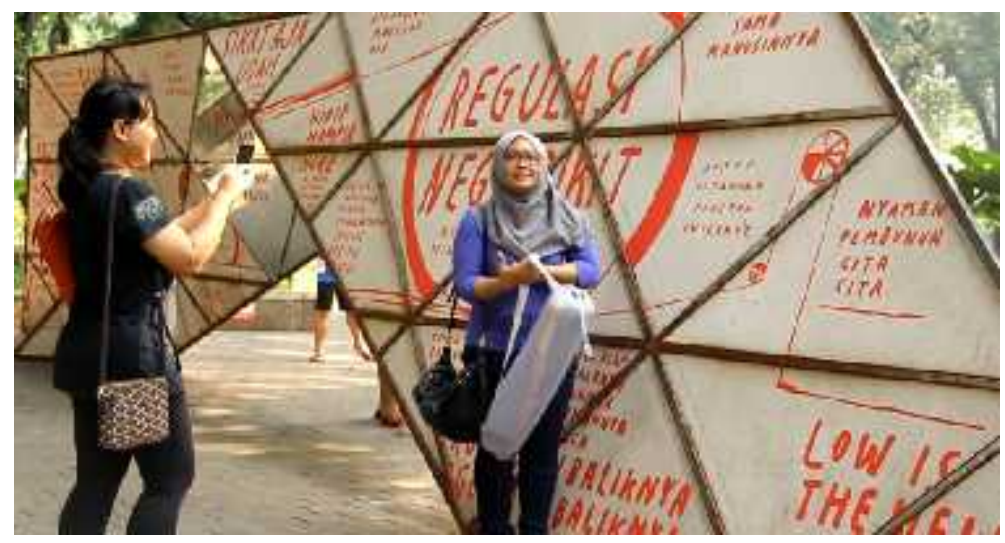

EXT/Taman Suropati/Day/Two Shot

Suasana Taman Suropati

Scene 6

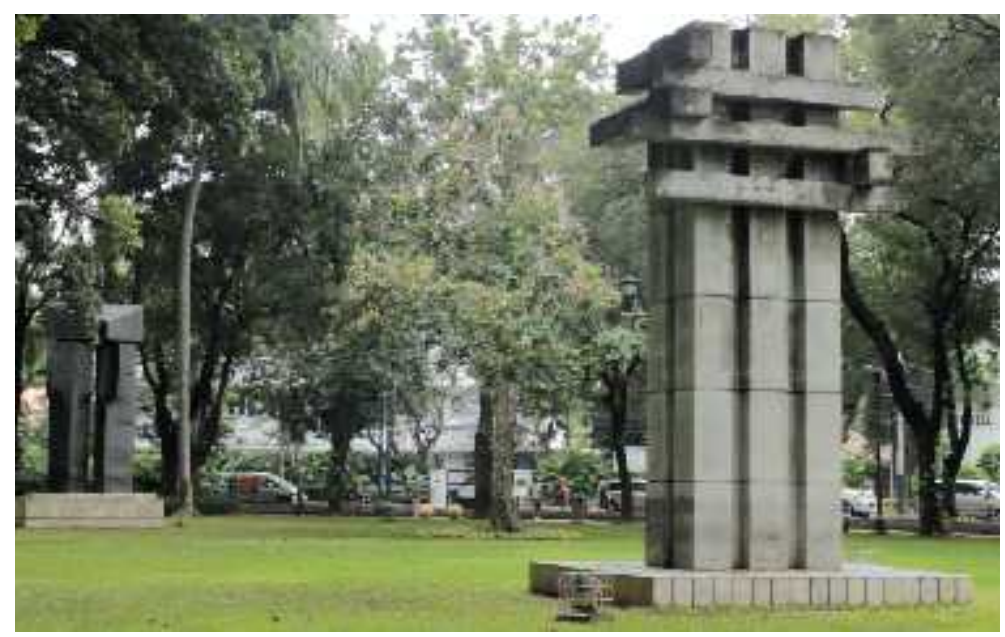

EXT/ Taman Suropati/Day/ Full Shot

Menampilkan Patung - Patung yang ada di taman Suropati 


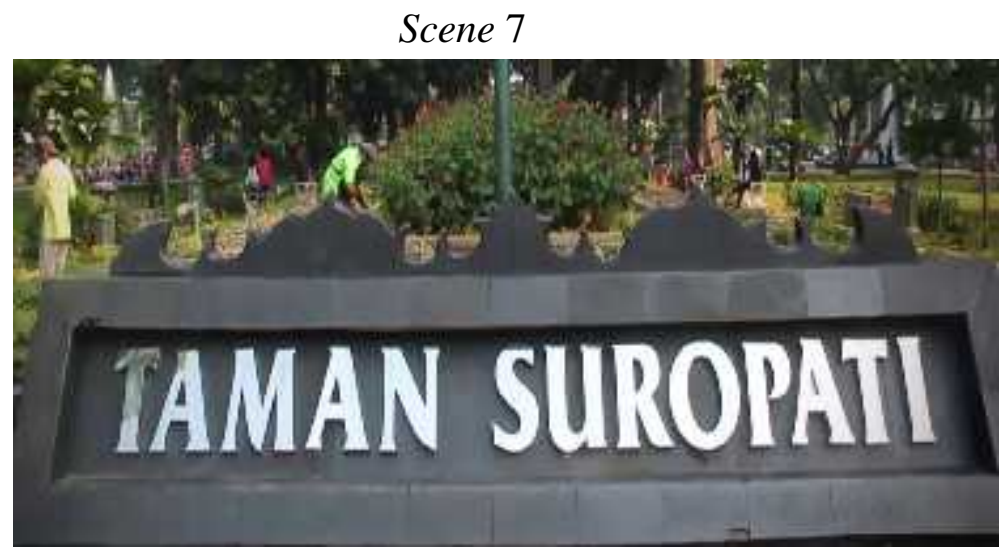

EXT/Taman Suropati/Day/Full Shot

Menampilkan tulisan taman Suropati

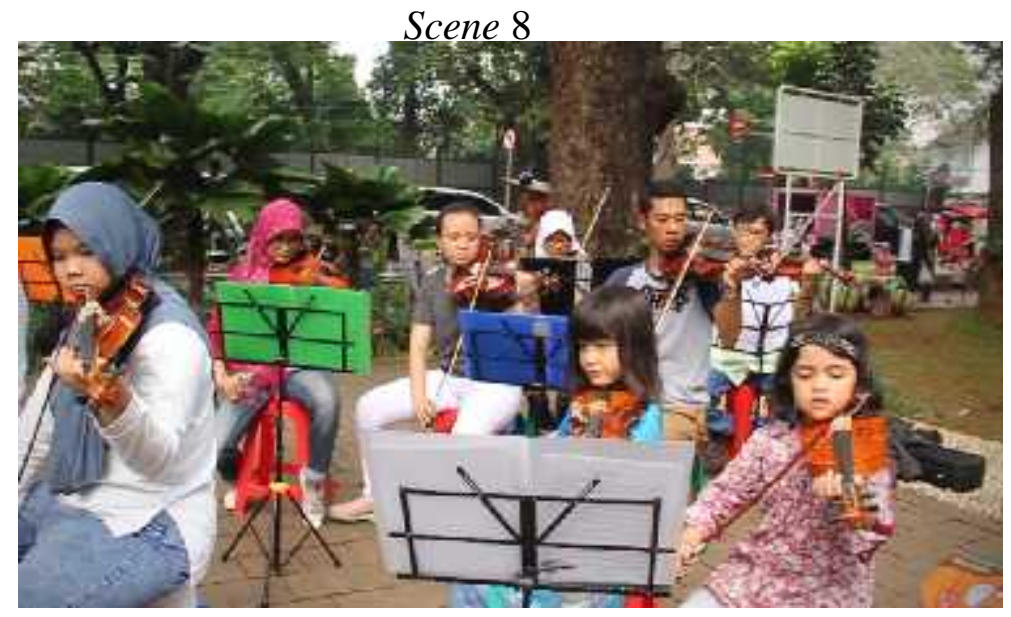

EXT/Taman Suropati/Day/Group Shot

Menampilka suasana anak - anak yang sedang latihan biola

\section{Postproduction}

Postproduction adalah tahapan terakhir dalam konsep produksi Mavib (KPM). Postproduction adalah proses finishing suatu karya sampai menjadi suatu video yang mampu menyampaikan sebuah informasi. 


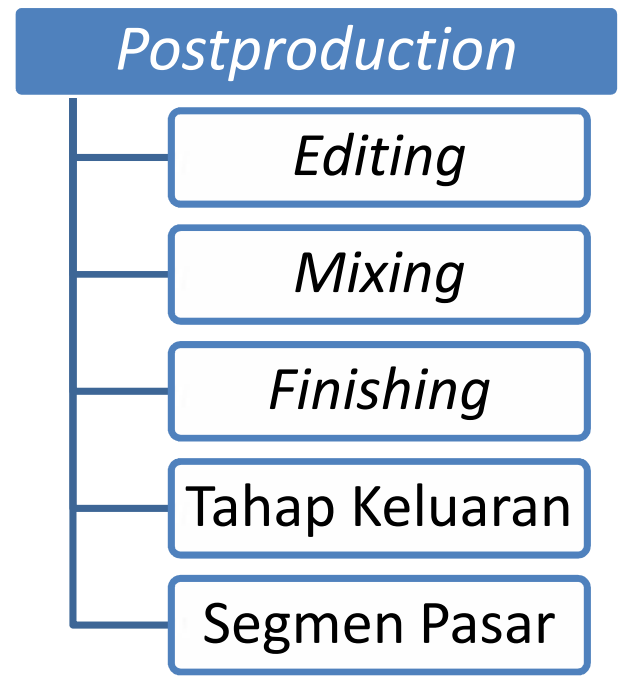

Gambar 3. Postproduction

\section{Kesimpulan}

Untuk menyajikan sebuah video dokumenter musik chamber yang informatif, maka dibutuhkan produksi video dokumenter dengan informasi yang up to date sesuai dengan perkembangan program televisi saat ini dengan footage yang terbaru, dikarenakan media audio visual menyampaikan rangkaian berupa gambar, teks, video, dan musik yang berfungsi untuk keperluan seperti menginformasikan dan memperkenalkan musik chamber taman suropati yang sudah memiliki sejarah panjang tentang aktivitas masyarakat jakarta.

\section{Daftar Pustaka}

[1] Ayuningtyas, Melvy. 2011. Ngedit Video Dengan Adobe Premiere Pro, Bekasi : Dunia Komputer.

[2] Desrianti, Dewi Immaniar. Untung Rahardja. Reni Mulyani. 2012. Audio Visual As One Of The Teaching Resources On Ilearning. Journal CCIT Vol. 5 No. 2. Tangerang : Raharja.

[3] Emriadi, Haviz. 2014. Perancangan Video Feature Dokumenter Industri Tambang Batu Kapur Bukit Tui Padang Panjang. Padang : Universitas Negeri Padang.

[4] Ilham. 2010. Entertainment Directory Book 2010. Jakarta : Gramedia

[5] Iwan, Sandi. 2013. Perancangan Video Dokumenter Olahraga Ekstrim "Skateboard" Surabayask8. Surabaya : UPN "Veteran" Jawa Timur.

[6] Nugroho, Fajar. 2012. Cara Pintar bikin film dokumenter, Yogyakarta : Indonesia Cerdas

[7] Oktavia, Siti Nur. 2015. Perancangan Film Dokumenter "Ketika Hati Vol.3 No.1 - Februari 2017 
Berbicara, Udara Membisikkannya Lewat Telingaku. Yogyakarta : Institut Seni Indonesia Yogyakarta.

[8] Putra, Dwiky Darmawan. 2014. Perancangan Video Dokumenter Penambang Pasir Sungai Progo Kecamatan Srandakan. Yogyakarta : AMIKOM Yogyakarta.

[9] Putri, Yuliani Intan. 2013. Perancangan Video Dokumenter Batik Khas Di Pekalongan. Salatiga : Universitas Kristen Satya Wacana

[10] Rahmawati, Indah. 2011. Menjadi Sutradara Televisi : Dengan Single dan Multi Kamera. Jakarta : Grasindo.

[11] Wardhani, Rahmi Kesuma. 2014. Perancangan Video Dokumenter "Autisme". Bandung : Institut Teknoogi Bandung. 